THE POSTGRADUATE
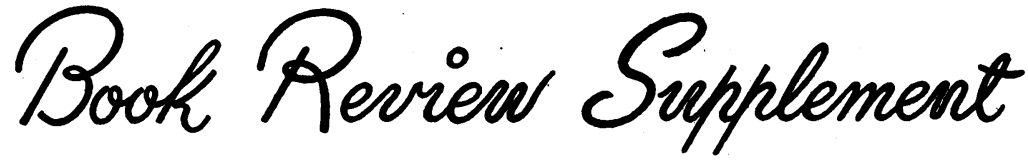

\section{THE CHILD IN HEALTH AND DISEASE}

Edited by C. G. GruleE, M.D., and R. C. Eley, M.D. 2nd Edition. Pp. xvi $+1,255$, with 304 illustrations. London: Ballière, Tindall and Cox. 1952. II 4 S.

\section{FANCONI AND WALLGREN'S TEXTBOOK OF PAEDIATRICS}

Edited by W. R. F. Collis, M.A., M.D., F.R.C.P., F.R.C.P.I., D.P.H. Pp. $x x+1,104$, with 440 illustrations. London: William Heinemann. 1952. $£ 77 \mathrm{~s}$.

General textbooks of paediatrics tend to fall into two groups. There is the one-man work, based largely on personal experience, containing a simple account of normal development and descriptions of the common problems and diseases of childhood and intended to be read through by the undergraduate. In the second group is the larger comprehensive textbook with many contributors, which no one, however greedy for erudition, would be prepared to read from cover to cover, but which serves a useful purpose as a work of reference in enabling one to obtain more complete information about any paediatric subject. The chapters of such a book should be balanced and up-to-date reviews of their subjects and should be followed by references to important original papers.

Such a work is the second edition of the American textbook by Grulee and Eley and written by 87 contributors, and in scope it may be compared to the English 'Garrod, Batten and 'Thursfield' or the American 'Mitchell-Nelson.' The Continental textbook 'Fanconi and Wallgren,' on the other hand, seems to belong to neither group. In length it is about two-thirds that of the American book and the subject matter tends to be too unbalanced for a student and yet too incomplete as a work of reference. Moreover, there are comparatively few references to original papers.

The arrangement of the subject matter in ' Grulee and Eley' is unusual. Due, no doubt, to the special interests of Dr. Eley, great emphasis is laid on infectious disease. Streptococcal bacteraemia, tonsillitis, otitis media, mastoiditis, sinusitis, peritonitis, vaginitis, osteomyelitis, etc., are all considered in the chapter on 'Streptococcosis' instead of being found, as is more con- ventional, in chapters devoted to diseases of each system. In some ways this is confusing, as the acute pyogenic meningitides, for instance, are considered in no less than six different parts of the book, but on the whole the reviewer feels that this method of presentation has much to commend it.

There is a certain lack of balance between chapters; perhaps the most obvious example is that 19 pages are devoted to pancreatic fibrosis, whilst coeliac disease is accorded no recognition. But some inequality of treatment is inevitable in such a textbook. Amongst the new chapters is one already mentioned-on pancreatic fribosis-and one on erythroblastosis foetalis by experts in these fields from the Boston Children's Hospital. Special mention must also be made of the chapter 'Diseases of the Nervous System' by Dr. D. Buchanan, which is, in the reviewer's opinion, the best to be found in any textbook of children's diseases.

In both books there are indications of expansionist activities amongst paediatricians in the shape of chapters on adolescence and information on this neglected subject is welcome.

The Continental textbook is an English translation of the 'Lehrbuch der Padiatrie' by Fanconi and Wallgren. This edition has been prepared by Dr. Collis of Dublin, who is also a contributor. The translation has been made by Dr. E. Kawerau who, in a disarming introductory note, explains some of the difficulties and problems he has had to face. In general these have been remarkably well overcome and the style is easy to read and none the worse for being unfamiliar. There are, however, passages such as "From the age of four months, a healthy child begins to "'make strange ",' which means little more even in their contexts and these should surely have been altered in the editing.

The authors are 19 distinguished paediatricians, mostly from Sweden and Switzerland, but also from seven other European countries.

Although full of useful and interesting information the book suffers from unevenness of presentation. The descriptions of common and important subjects are frequently too brief, whilst much space is devoted to highly specialized aspects of paediatrics. Thus the chapter on the pneumonias is only onesixth the length of that in 'Grulee and Eley,' whilst in the section on heart disease only four lines are allotted to atrial septal defect, although much space is occupied by diagrams of electrocardio- 
grams, phonocardiograms and angiocardiograms.

One noteworthy feature is the chapter on constitution and diathesis, subjects seldom considered in English textbooks. The relationship between external appearance and character and predisposition to disease is a subject that fascinates, even if it does not always convince. Special mention must be made of the excellent chapter on tuberculosis by Professor Wallgren.

The illustrations in 'Grulee and Eley' are good; the even more numerous illustrations in 'Fanconi and Walgren' are superlatively good. In particular the colour photographs of skin diseases are the best the reviewer has ever seen. This excellence is partly due to the superior paper and partly to the use of full-plate reproductions; perhaps this also accounts for the added expense of the book.

The reviewer was rather surprised to find few differences in outlook between American and Continental paediatricians on subjects of major importance. An exception may be found on pages 27 of 'Grulee and Eley' and 74 of 'Fanconi and Wallgren,' which read respectively, 'There are only a few things which a child must do, and only a very few he should not do. The most efficacious way of slowly teaching children these few restrictions is by placing them in their play pen or play room when their behaviour is too disturbing or overly destructive, and thus curtailing their freedom. This can be done without anger on the part of the parents or stimulation of fear in the mind of the child; it is the only form of force that is necessary' and 'The child must be introduced into the society of other children. To overcome his egocentric attitude it is generally necessary to use more or less severe methods of punishment, such as a rap on the fingers.'

Perhaps this shows that on the subject of rearing normal children there is more divergence of opinion than on most other paediatric problems!

The senior student, general practitioner or paediatrician who wishes to buy a textbook of advanced paediatrics can be advised confidently that 'Grulee and Eley' is the equal of the other textbooks mentioned. ' Fanconi and Wallgren' can be equally confidently recommended as bedtime reading for the more experienced paediatrician in the certainty that it will provide him with much useful and sometimes unusual information, as well as entertainment. Both books should be in every medical library.

\section{MORBUS ALHZEIMER AND MORBUS PICK}

By T. SJögren, H. Sjögren and $\stackrel{\circ}{A}$. G. H. LiNDGREN. Pp. 1 52, illustrated. Copenhagen: Ejnar Munksgaard. 1952.

This erudite genetic, clinical and pathoanatomical study is only for advanced students of genetics, psychiatry, neurology and neuropathology, and to them it is commended.

J.D.W.P.
A TEXTBOOK OF MENTAL DEFICIENCY (AMENTIA)

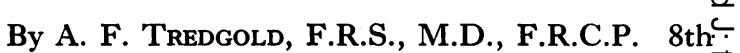
Edition. Pp. xvi +546 , with 48 illustrations. $\overrightarrow{\bar{F}}$ London: Ballière, Tindall and Cox. 1952 37s. $6 \mathrm{~d}$.

The medical textbooks published in the 2oth $\frac{\overline{\bar{c}}}{\overline{\frac{\sigma}{2}}}$ century which have earned for themselves a world-ब wide reputation are few in number. Tredgold' $s_{0}$ mental deficiency takes a leading place in that ${ }^{(s)}$ select few. The appearance of the eighth edition $\overrightarrow{0}$ reminds us that the first appeared as far back asr 908 and that the new edition made its appearance $\vec{\omega}$ the day before the death of its distinguished author. His son, Dr. R. F. Tredgold, has assisted in theo preparation of this edition and it is to be hoped that 3 the future of the work may be assured for manyig years to come.

Tredgold's textbook has for long been the $\mathscr{E}^{\mathscr{U}}$ essential textbook in English for all those needingiv up-to-date information and authoritative discussion $\overrightarrow{0}$ on the causes, clinical types and treatment of mental defectives. This new edition remains up to date응 while preserving its author's cautious attitude torecent work on etiology or treatment which may not $>$ yet be fully confirmed by parallel clinical research or을 experience.

The clinical sections of the book are well knophif for their excellence. They are often dramatic in their clarity of description; an example is to tersely phrased paragraph which describes absolutte or complete idiocy. These sections are well illustrated by plates (some of which are new) and by many descriptive cases. The discussion of the $\frac{\circ}{\mathbb{2}}$ clinical types is thorough and presents the latest views on pathology and treatment. The rarities are $\overrightarrow{\overrightarrow{0}}$ all there and in this respect it can be recorded that 3 the book contains an admirable index which functioned accurately on every occasion it was wantedo by the reviewer. As a work of reference the clinical sections are unsurpassed.

The chapter on aetiology shows considerable $\overline{0}$ change and contains references to recent work on? ante-natal pathology as a cause of defect. In the $\delta$ discussion on what are often called 'stressing agents' acting during pregnancy the author refers $\mathrm{O}$ to Gregg's clinical work on the effects of maternal rubella during the early months of pregnancy. $\mathrm{He}$ ? also refers to the work of experimental embryologists, such as Warkany and Hale, on the dire N effects of lack of vitamin A during pregnancy. There is no mention of the interesting work of $N$ Ingalls and his co-workers on the results of maternal anoxia during pregnancy on the offspring of mice, $O$ work which opens up new fields of study in causation and therefore prevention. In this chapter on aetiology expert medical readers may like to know more of the author's claim to have seen cases in which the prolonged use of a soluble contraceptive ${ }^{T}$ pessary has failed and been followed by the birth $\frac{+}{+}$ of a defective child. The claim is sure to have been $\stackrel{\oplus}{\stackrel{P}{9}}$ 